Research Article

\title{
Qualitative Analysis of Air Freshener Spray
}

\author{
Fatima Ibrahim ALshaer, Dalal Fuad ALBaharna, Hafiz Omer Ahmed (D), \\ Mohammed Ghiyath Anas, and Jasem Mohammed ALJassmi \\ Department of Environmental Health, College of Health Sciences, University of Sharjah, Sharjah, UAE \\ Correspondence should be addressed to Hafiz Omer Ahmed; hafizomer@sharjah.ac.ae
}

Received 10 April 2019; Revised 5 September 2019; Accepted 19 September 2019; Published 5 November 2019

Academic Editor: Giuseppe La Torre

Copyright (C) 2019 Fatima Ibrahim ALshaer et al. This is an open access article distributed under the Creative Commons Attribution License, which permits unrestricted use, distribution, and reproduction in any medium, provided the original work is properly cited.

\begin{abstract}
Air fresheners contain various chemicals that may or may not be harmful to human health and the environment. These products are widely used in different settings such as homes, schools, offices, and hospitals with ignorance of their real ingredients and their relative health effects. Thus, this preliminary study was carried out to identify the presence of different compounds in spray air fresheners that were not disclosed on the product's label. Four different brands of spray air fresheners were selected randomly from a local store, in which two were of mid-to-high cost and the remaining two of low cost. The samples were analyzed using gas chromatography/mass spectrometry headspace, in which single components of the samples were identified by the mass spectrometry detector. The results were shown as a chromatogram of several peaks, each representing different compounds. The chemicals found in the samples include; lilial, galaxolide, benzenemethanol, musk ketone, butylated hydroxytoluene, and linalool. These chemicals may cause irritation and other health problems. However, none of them were revealed on the product's label. The study concludes that air fresheners need to be free of any toxic or harmful chemicals and include natural ingredients instead.
\end{abstract}

\section{Introduction}

Air fresheners are chemical products that have been used in the field of environmental sanitation for decades [1]. These products are used in different settings, including dwellings, hospitals, offices, schools, hotels, restrooms etc. They are available in various forms such as incense, scented candles, oils, disks, aerosol sprays, electric diffusers, and gels. According to Jung et al. [2], air fresheners are indiscriminately used to mask the effects of the deodorizing and fragrant components in indoor environments.

The main purpose of using air fresheners is to get rid of disturbing odours that may result from different activities or processes within an area. They may consist of several ingredients that have the ability to provide a pleasant ambience. Nevertheless, drawbacks may also result due to their excessive usage. They consist of many chemicals that are not revealed on the product label as manufacturers are not required to disclose all ingredients [3]. These chemicals could be allergens, irritants, or even toxic [4]. Steinemann et al. [5] found numerous chemicals in air fresheners, such as acetaldehyde, acetone, benzaldehyde, and limonene that were not listed on the product label.

Numerous studies have been carried out by different researchers on the composition of air fresheners and their relative health effects. For instance, Fleming indicated that some compounds in such products including benzene derivatives, pinene and limonene, aldehydes, phenol, and cresol may pose serious health effects when reacting with other indoor pollutants. Other common chemicals that could be found in air fresheners include VOCs such as benzyl alcohol, toluene, myrcene, phthalates, artificial musks, lilial, and linalool $[6,7]$.

Air fresheners have been recognized as a primary source of volatile organic compounds throughout buildings from an indoor air-quality perspective. However, air fresheners have been related with adverse effects such as asthma attack, mucosal symptoms, infant illness, breathing difficulties, and migraine headaches from a health perspective [6]. In the previous two national surveys of the US population, breathing difficulties, headaches, and other health problems were reported by 19 percent population when exposed to 
TABle 1: Brief description of each chemicals used in the sample freshener.

\begin{tabular}{|c|c|c|c|c|c|}
\hline Sample & Cost & Packaging & Usage & Quantity & CAS \\
\hline Galaxolide & AED 105 & Glass bottle & Aroma/fragrance preparations & $30 \mathrm{ml}$ (1 fluid ounce) & $1222-05-5$ \\
\hline Lilial & AED 274 & Glass bottle & Aroma/fragrance preparations & $50 \mathrm{ml}$ & $80-54-6$ \\
\hline Benzenemethanol & AED 124 & - & - & $16 \mathrm{oz}$ & $202-859-9$ \\
\hline Musk ketone & AED 76.80 & Drum & Perfumery compound & $5.25 \mathrm{kgs}$ & - \\
\hline Butylated hydroxytoluene & AED 12.80 & Customized & Perfumery compound & $2 \mathrm{~kg}$ & - \\
\hline Linalool & AED 69.15 & Customized & Perfumery compound & $5 \mathrm{~g}$ & $78-70-6$ \\
\hline
\end{tabular}

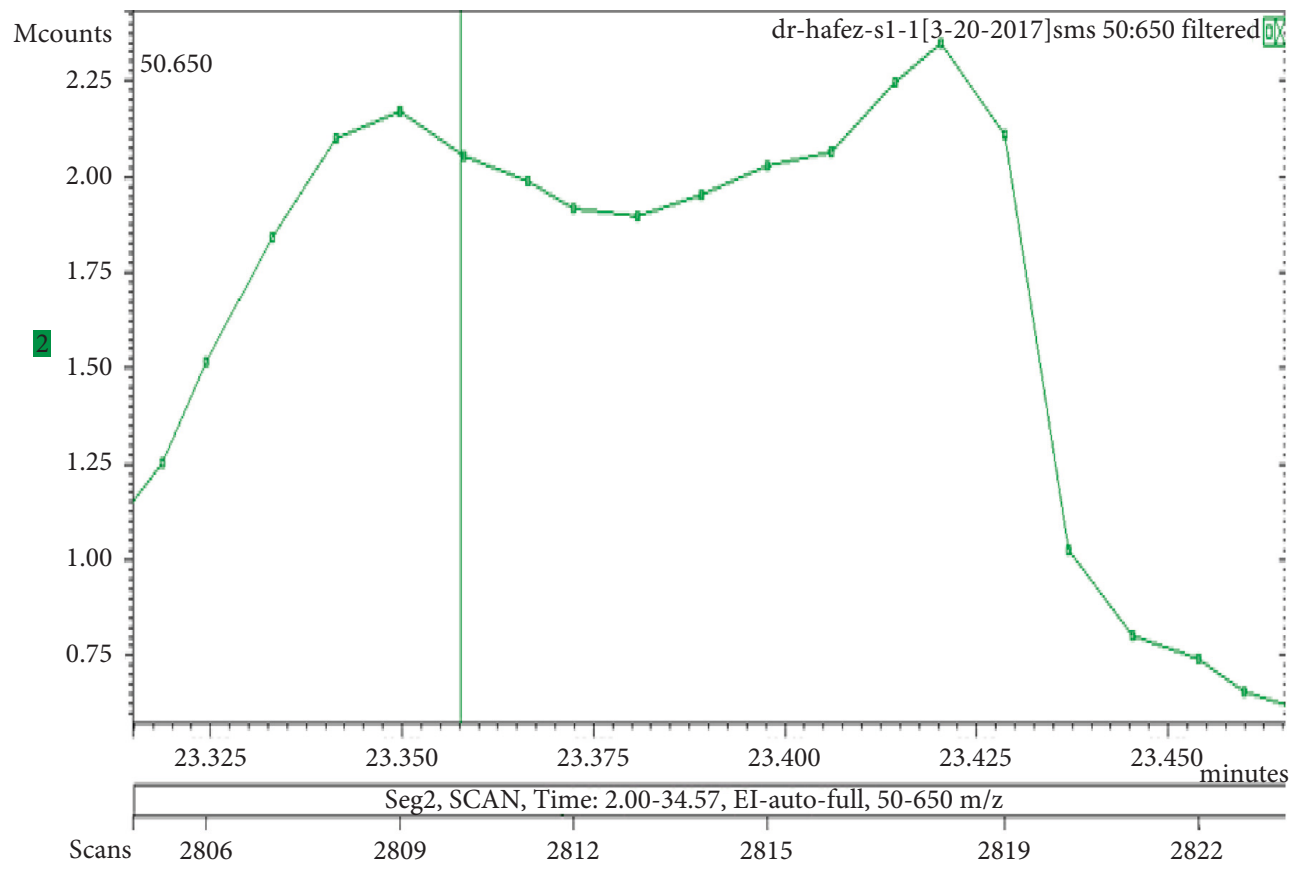

FIgURE 1: Chromatogram of galaxolide in air freshener sample 1.

deodorizers and air fresheners. 10.9 percent population reported health problems from the scent of laundry products vented outdoors $[7,8]$.

The contribution of a range of risk factors has been assessed by the World Health Organization to the stress of disease and indicated indoor pollution as the $8^{\text {th }}$ most important risk factor and accountable for 2.7 percent of the burden of disease, globally. Every year, indoor air pollution is accountable for the death of 20 individuals [9]. Concentrations of a number of volatile organic compounds are consistently higher indoors as compared to outdoors. Volatile organic compounds are comprised within household products, such as wood preservatives, aerosol sprays, cleansers, disinfectants, paints, paint strippers, moth repellents, air fresheners, hobby supplies, dry-cleaned clothing, stored fuels and automated products, and other solvents [10].

A National Environment Health Action Plan (NEHAP) has been launched by the French government in June 2004, for improving indoor air quality. The Ministries of Health, Labour, and Environment for evaluating health risks related with formaldehyde and other volatile organic ompounds indoors have been mandated by the French Agency for Environmental and Occupational Health Safety (AFSSET). In this regard, the role of AFSSET was to recognize everyday life products comprising or emitting formaldehyde and examine quantity-related human exposure by either direct or indirect sources [11].

Information lacks concerning the gaseous emissions of fragrance products in spite of the extensive indoor exposure and widespread use of fragrances to them [12]. In addition, 95 percent of the chemicals are synthetic compounds in fragrances that are derived from petroleum [13]. Humans have been exposed to specific compounds for assessing the safety of those compounds inhaled when examining the hazard of fragrance compounds [14].

It is important to carry out this study to increase awareness and understanding of their hidden ingredients becasue of the extensive use of air fresheners with the ignorance of their actual contents and their relative effects on humans and the environment. Therefore, the present study aims to identify the presence of different compounds in spray air fresheners that are not disclosed on the product's label.

\section{Material and Methods}

2.1. Study Design and Sample Collection. A qualitative, crosssectional study was conducted to determine the presence of toxic chemicals in the air fresheners. Four different brands of 


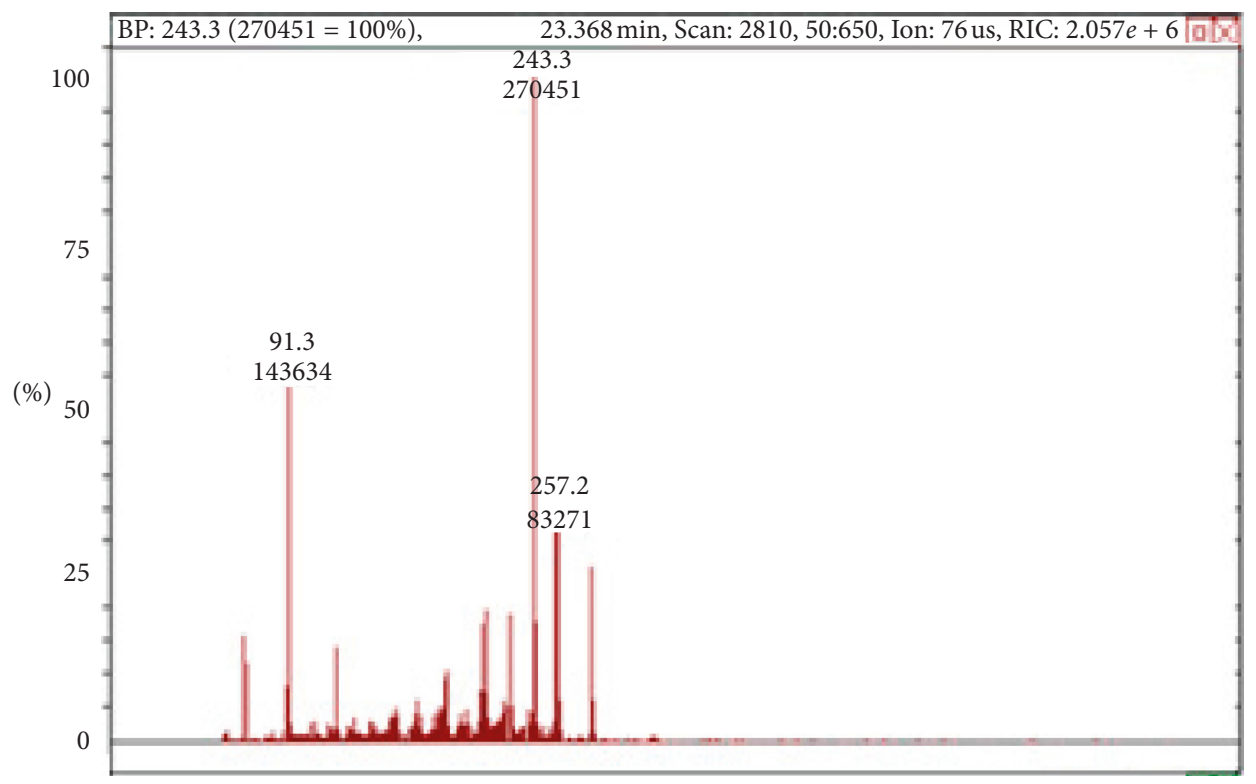

(a)

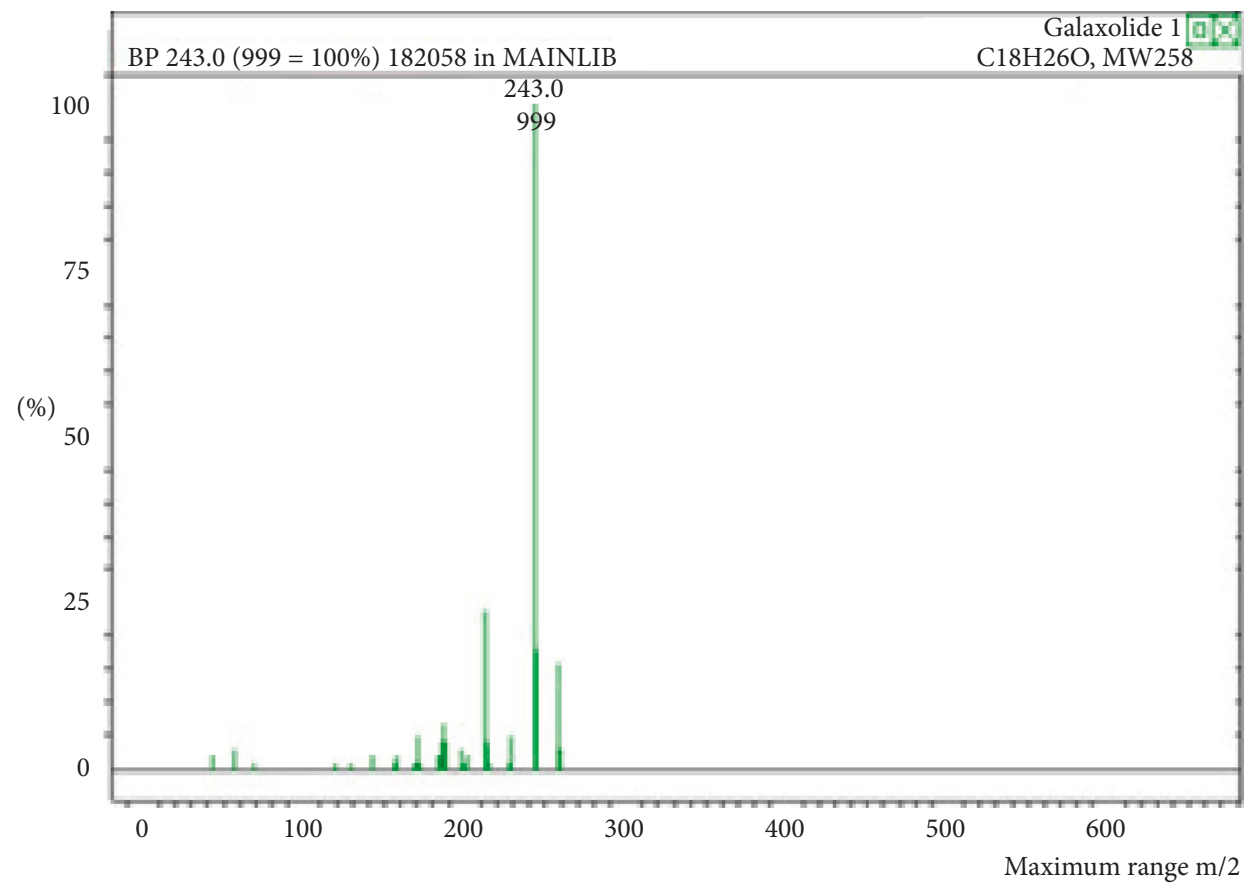

(b)

Figure 2: Mass spectrum of galaxolide in air freshener sample 1. (a) Air freshener analysis. (b) Main library of NIST11.

spray air fresheners were selected randomly from a local store, in which two were of mid-to-high cost and the remaining two of low cost.

2.2. Sample Analysis. Gas chromatography/mass spectrometry (GC/MS) headspace has been used to analyse the samples obtained from the air fresheners in environmental and analytical chemistry laboratories for the segregation and analysis of readily volatile compounds. The GC 3900/Saturn $2100 \mathrm{~T}$ GC/MS (ion trap) system was controlled using a Varian GC/MS workstation version 5.52 software. A volume of $1 \mu \mathrm{L}$ sample was injected into the column, where the separation of the chemical compounds in the air fresheners was performed using an HP VF- $5 \mathrm{~ms}$, $(30 \mathrm{~m} \times 0.32 \mathrm{~mm}$, $0.25 \mu \mathrm{m})$. Helium was used as the carrier gas at a flow rate of $1.0 \mathrm{~mL} / \mathrm{min}$, and the injector temperature was at $230^{\circ} \mathrm{C}$. The temperature program of the column oven was started at $50^{\circ} \mathrm{C}$, was held for $1 \mathrm{~min}$, ramped at $7^{\circ} \mathrm{C} / \mathrm{min}$ to $250^{\circ} \mathrm{C}$, and held for 5 mins.

The conditions for the ion trap mass spectrometer were as follows:

(i) Ionization mode; EI (70 ev) 


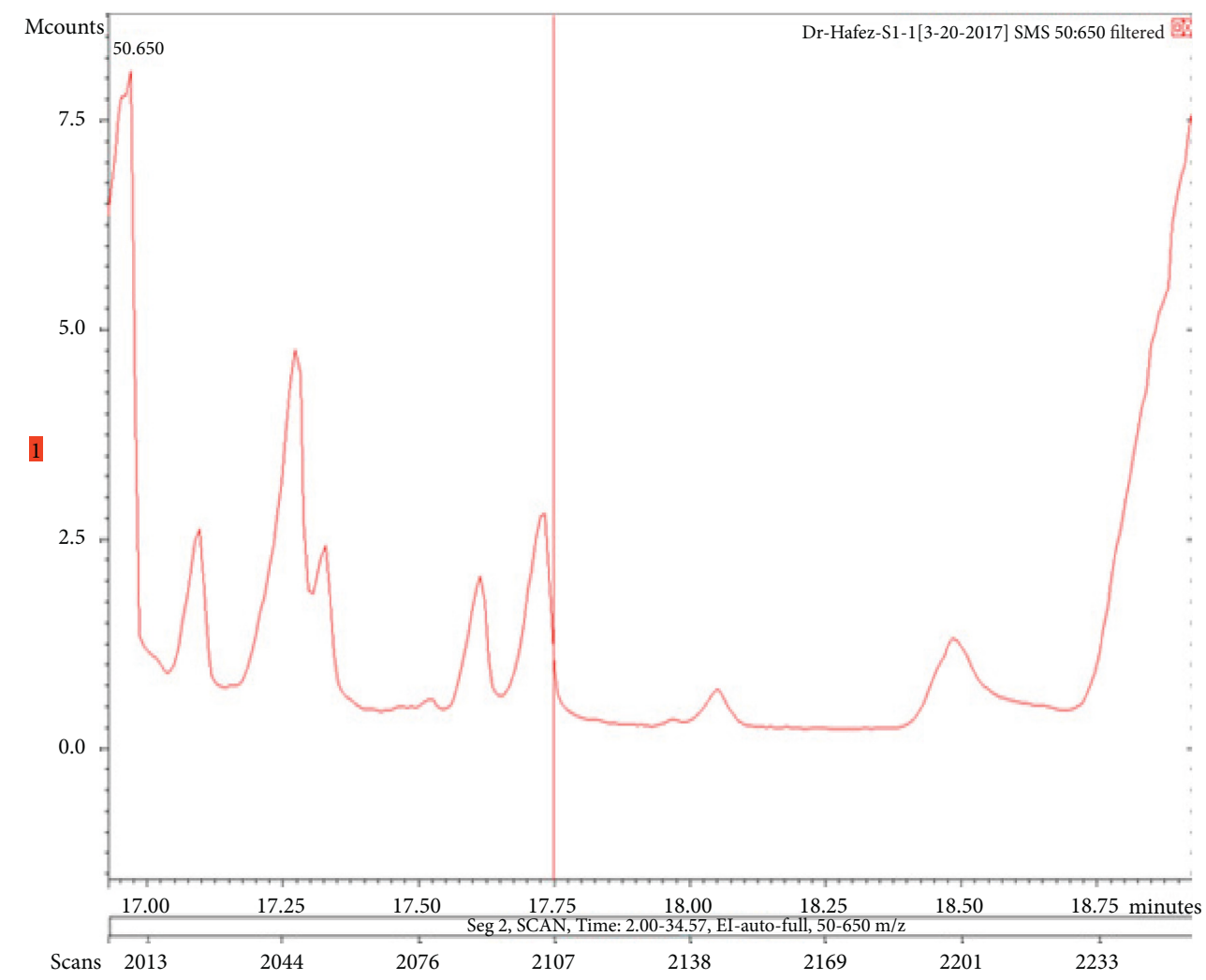

Figure 3: Chromatogram of lilial in air freshener sample 1.

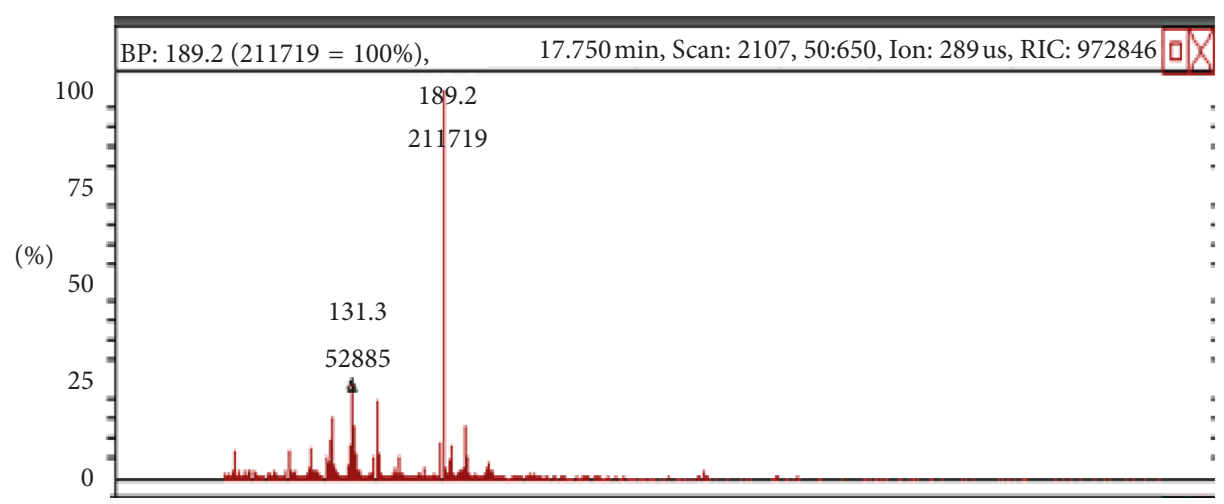

(a)

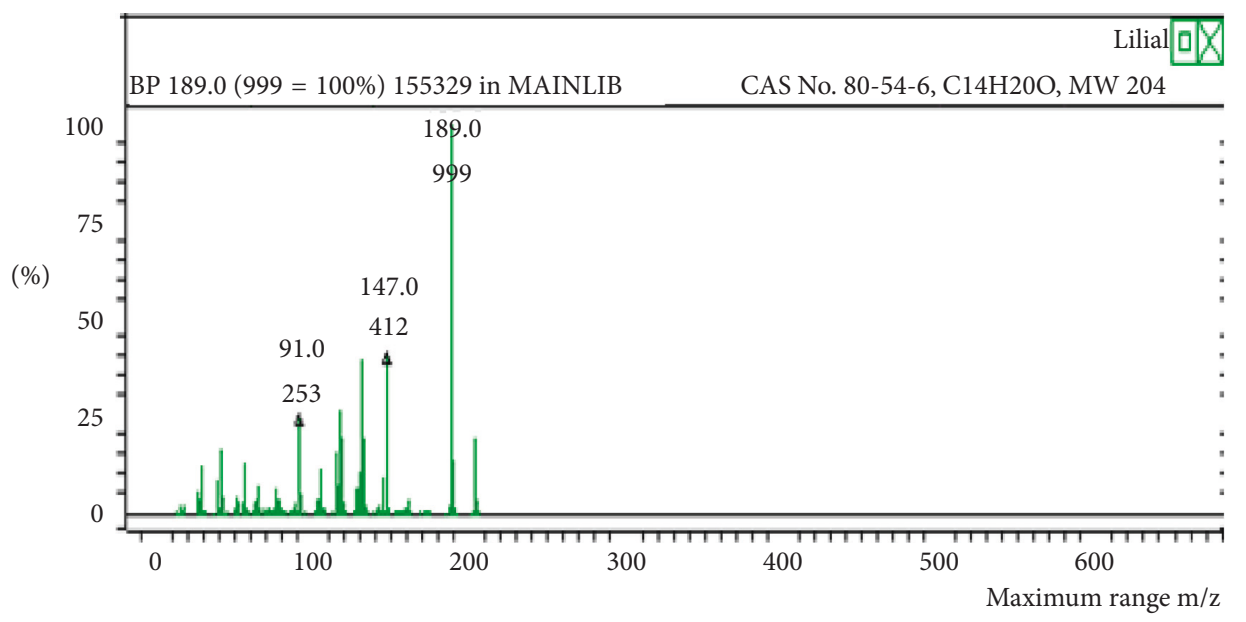

(b)

FIGURE 4: Mass spectrum of lilial in air freshener sample 1. (a) Air freshener analysis. (b) Main library of NIST11. 


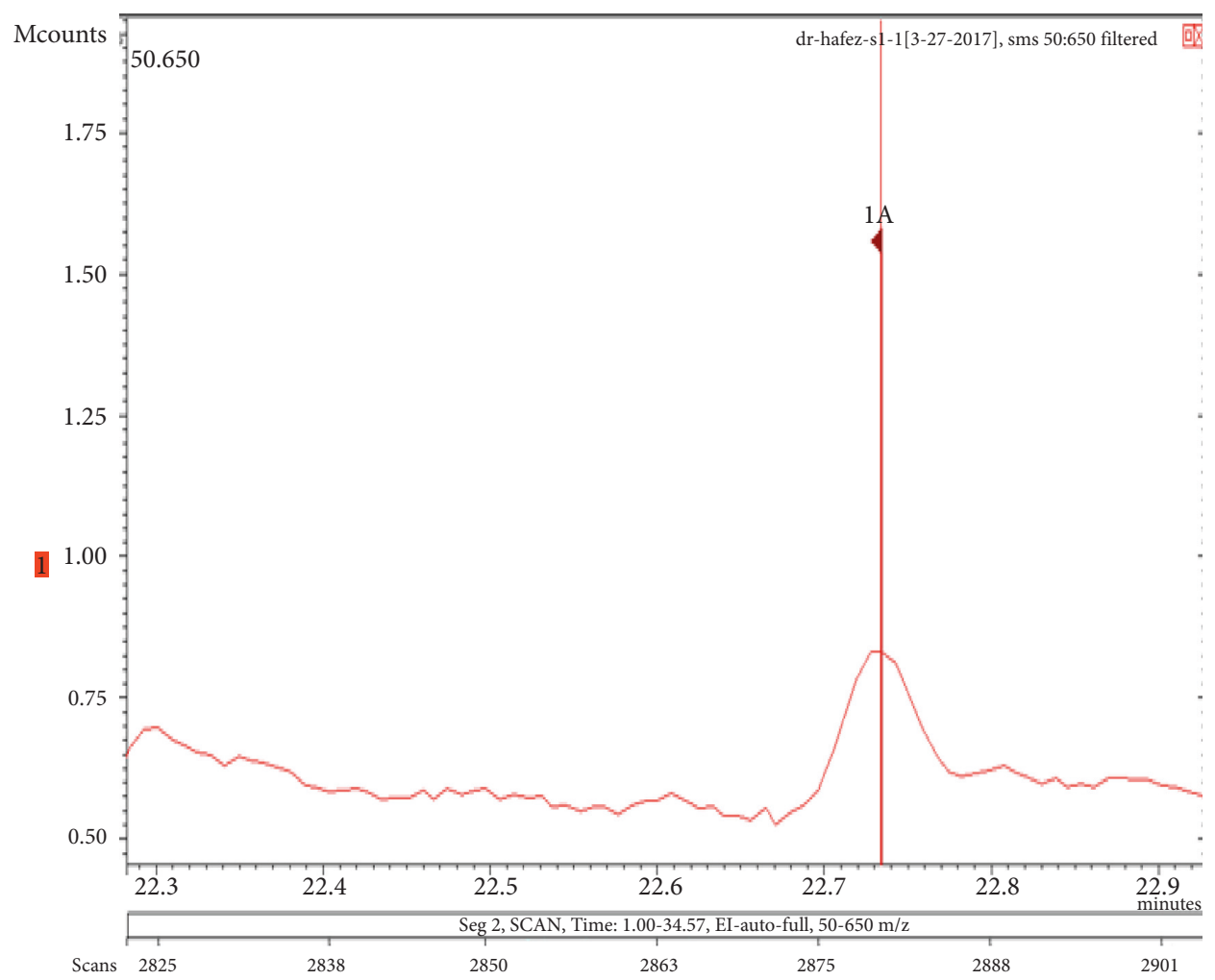

Figure 5: Chromatogram of galaxolide in air freshener sample 2.

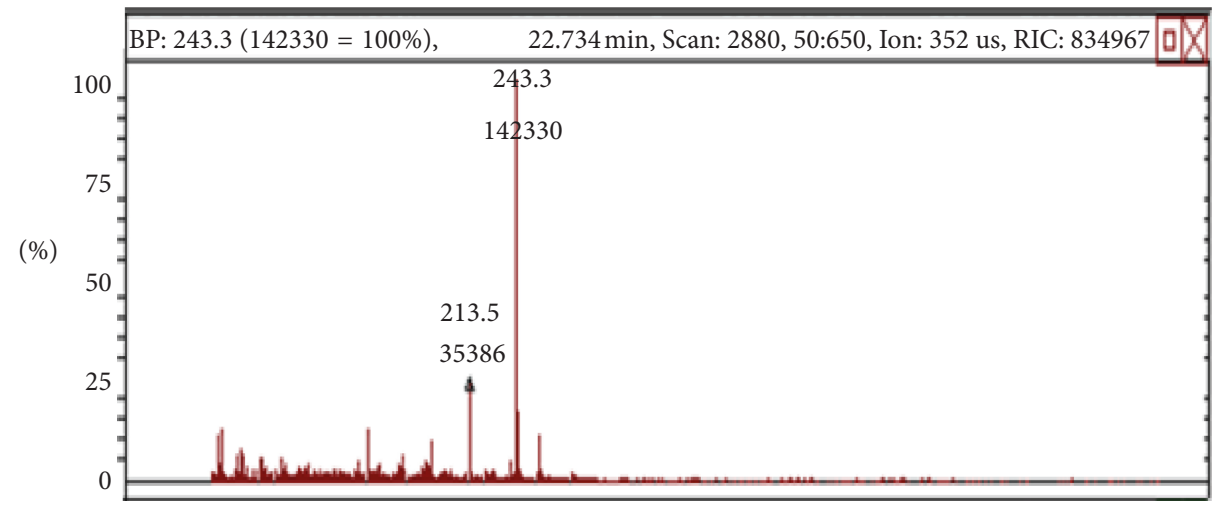

(a)

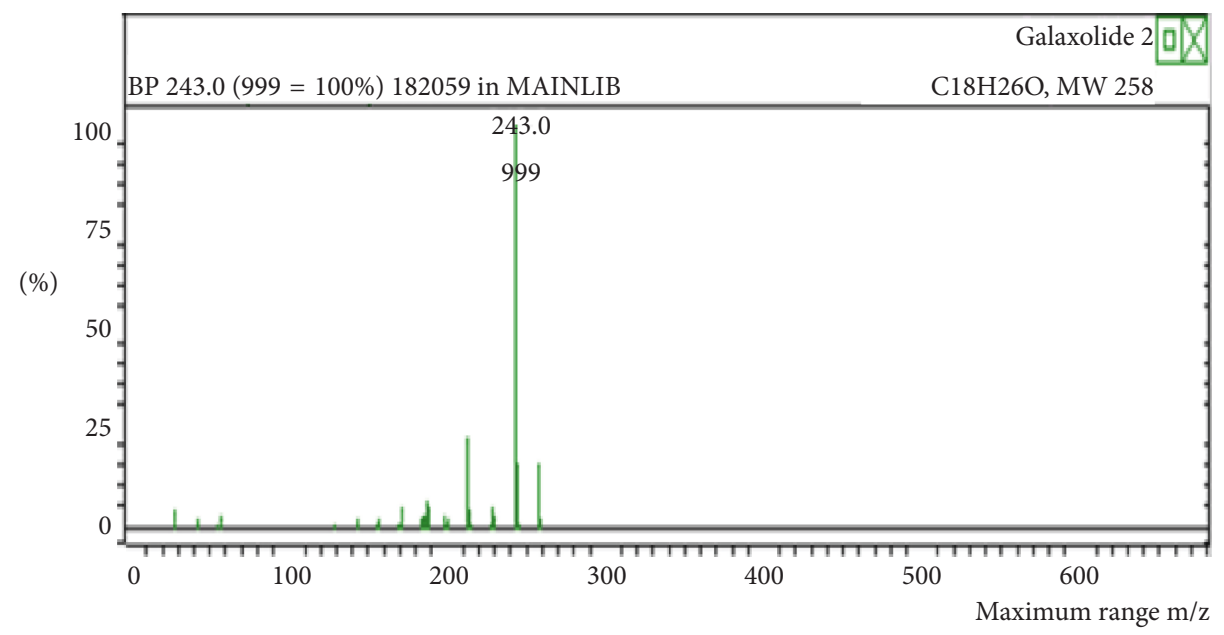

(b)

FIgure 6: Mass spectrum of galaxolide in air freshener sample 2. (a) Air freshener analysis. (b) Main library of NIST11. 


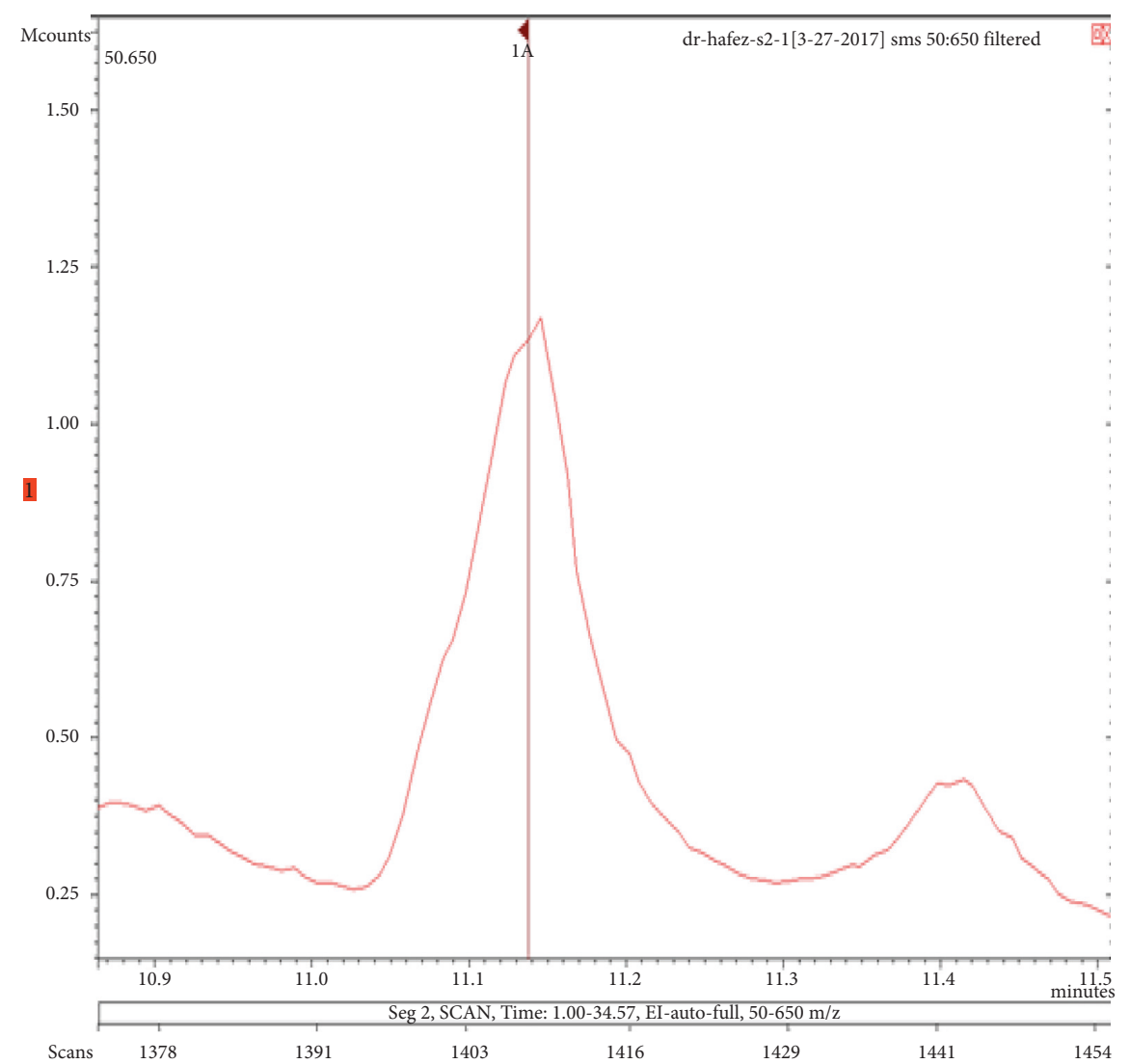

FiguRE 7: Chromatogram of benzenemethanol in air freshener sample 2.

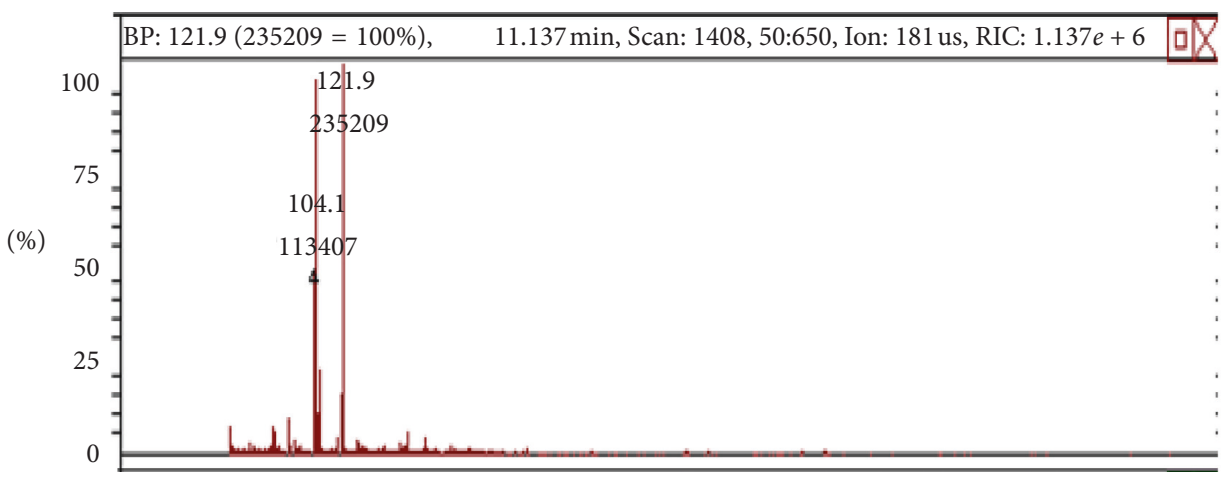

(a)

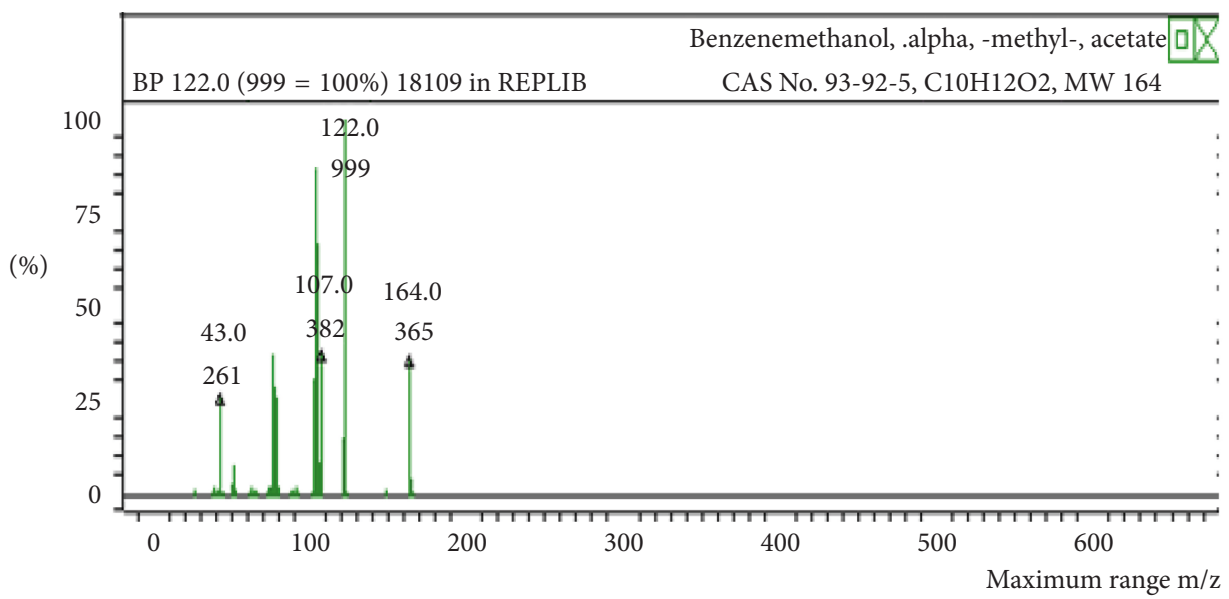

(b)

Figure 8: Mass spectrum of benzenemethanol in air freshener sample 2. (a) Air freshener analysis. (b) Main library of NIST11. 


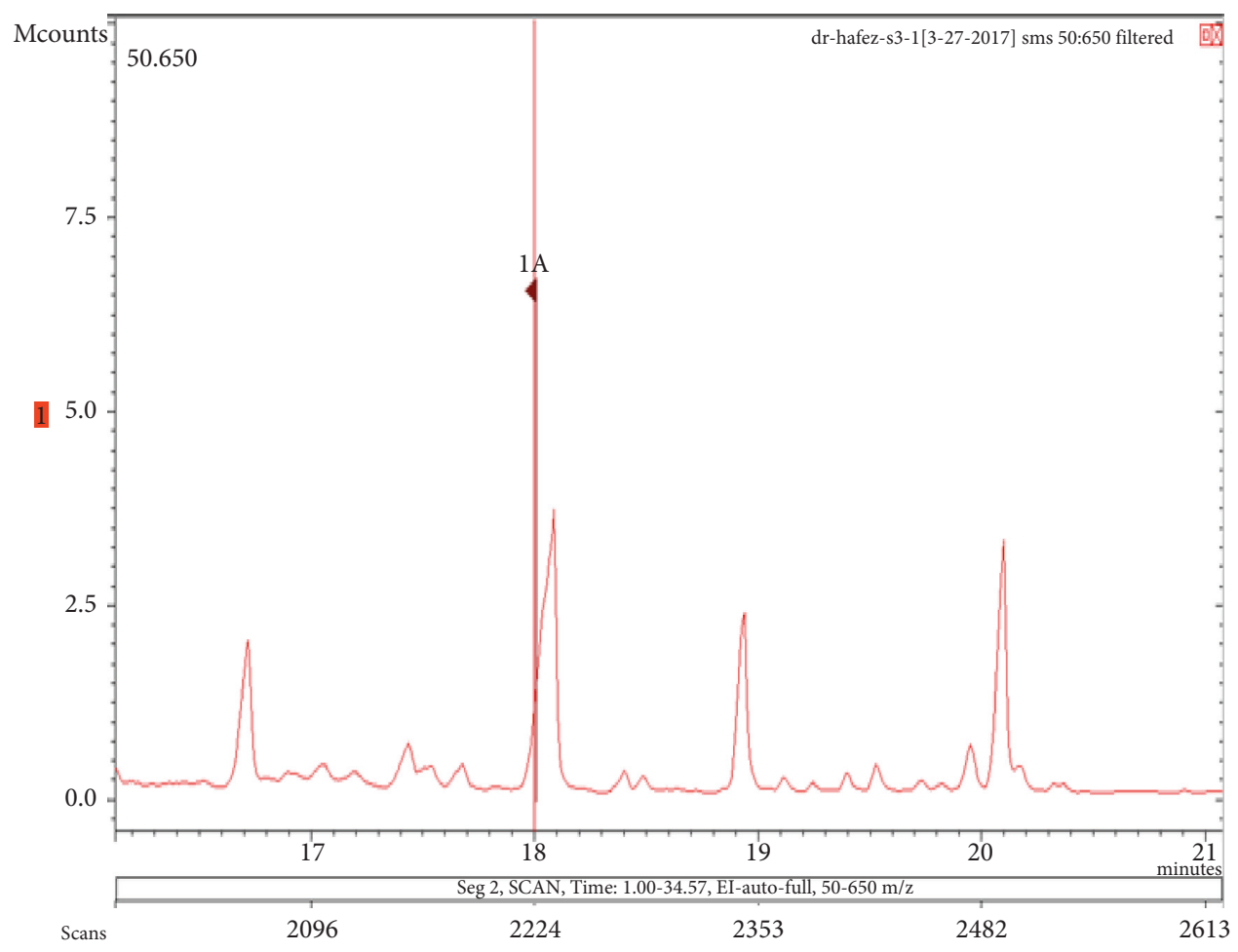

FIgURE 9: Chromatogram of benzenemethanol in air freshener sample 3.

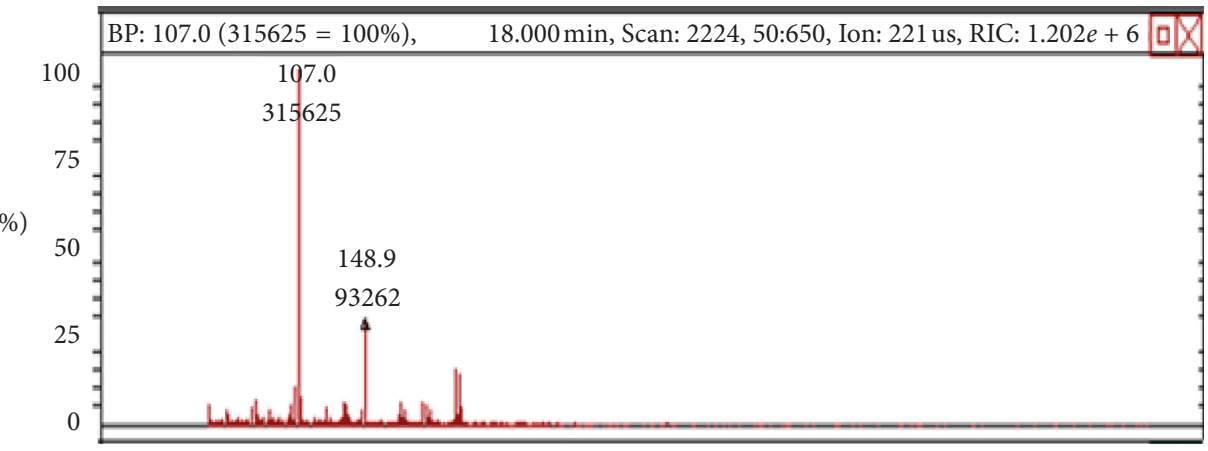

(a)

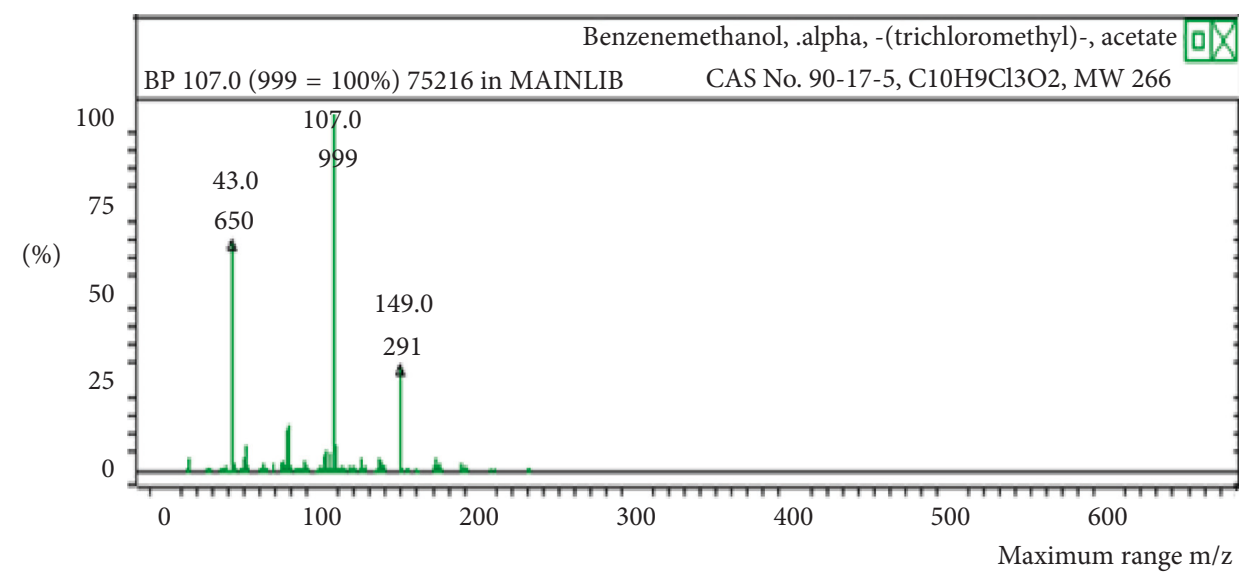

(b)

Figure 10: Mass spectrum of benzenemethanol in air freshener sample 3. (a) Air freshener analysis. (b) Main library of NIST11. 


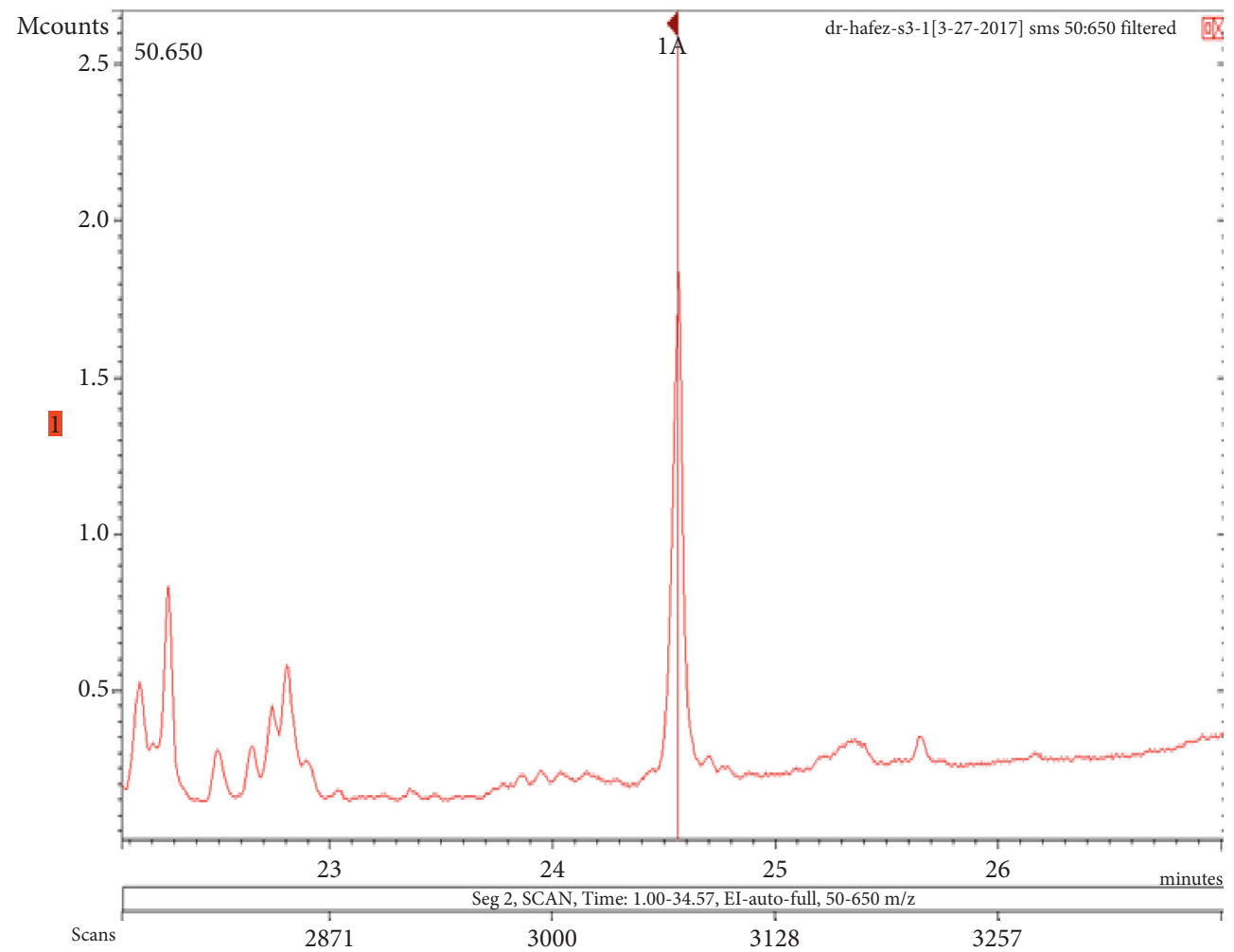

FIGURE 11: Chromatogram of musk ketone in air freshener sample 3.

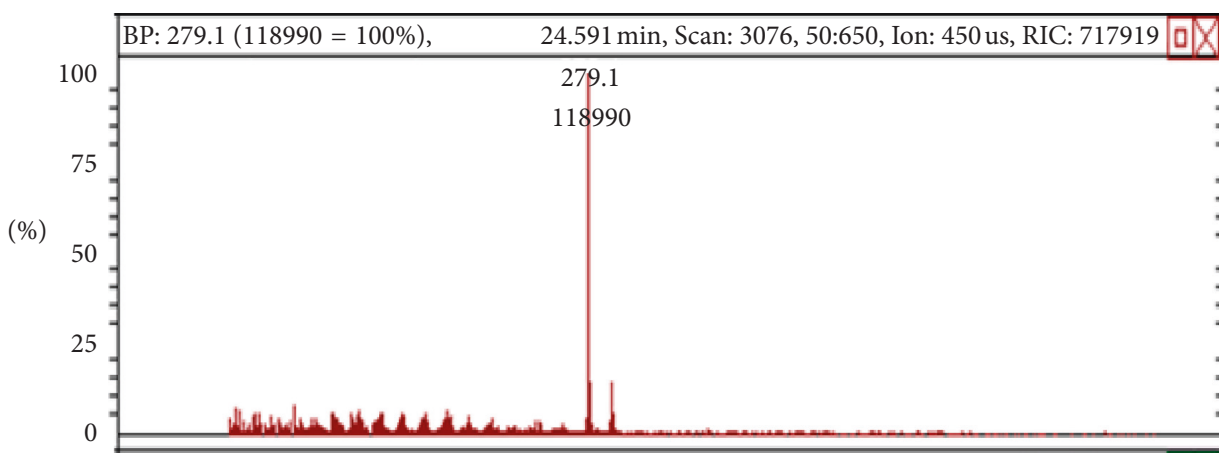

(a)

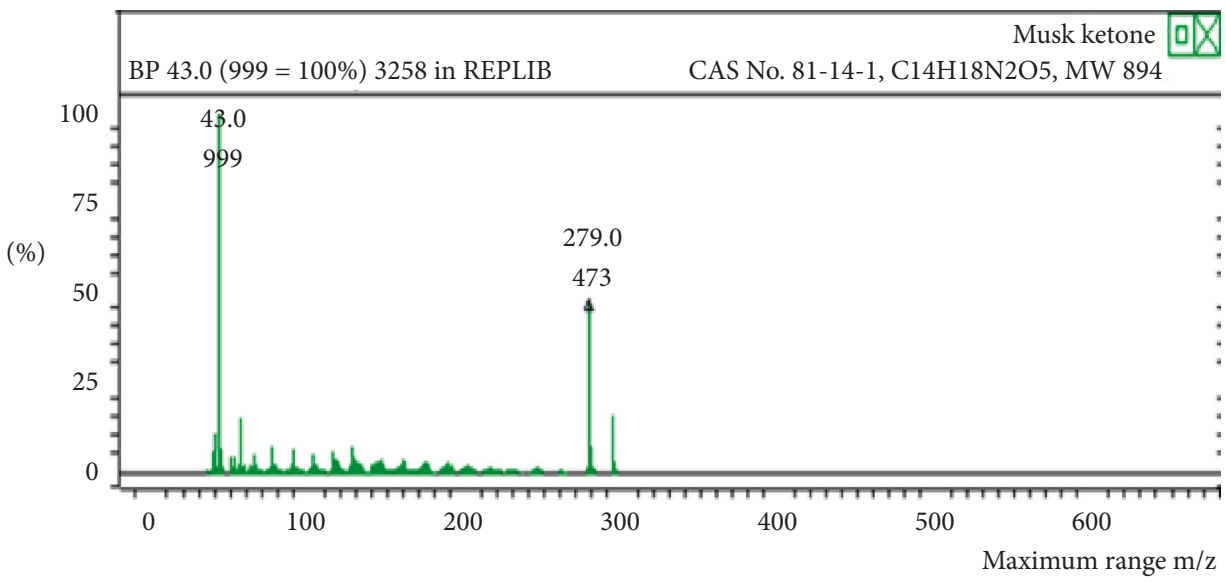

(b)

FIGURE 12: Mass spectrum of musk ketone in air freshener sample 3. (a) Air freshener analysis. (b) Main library of NIST11. 


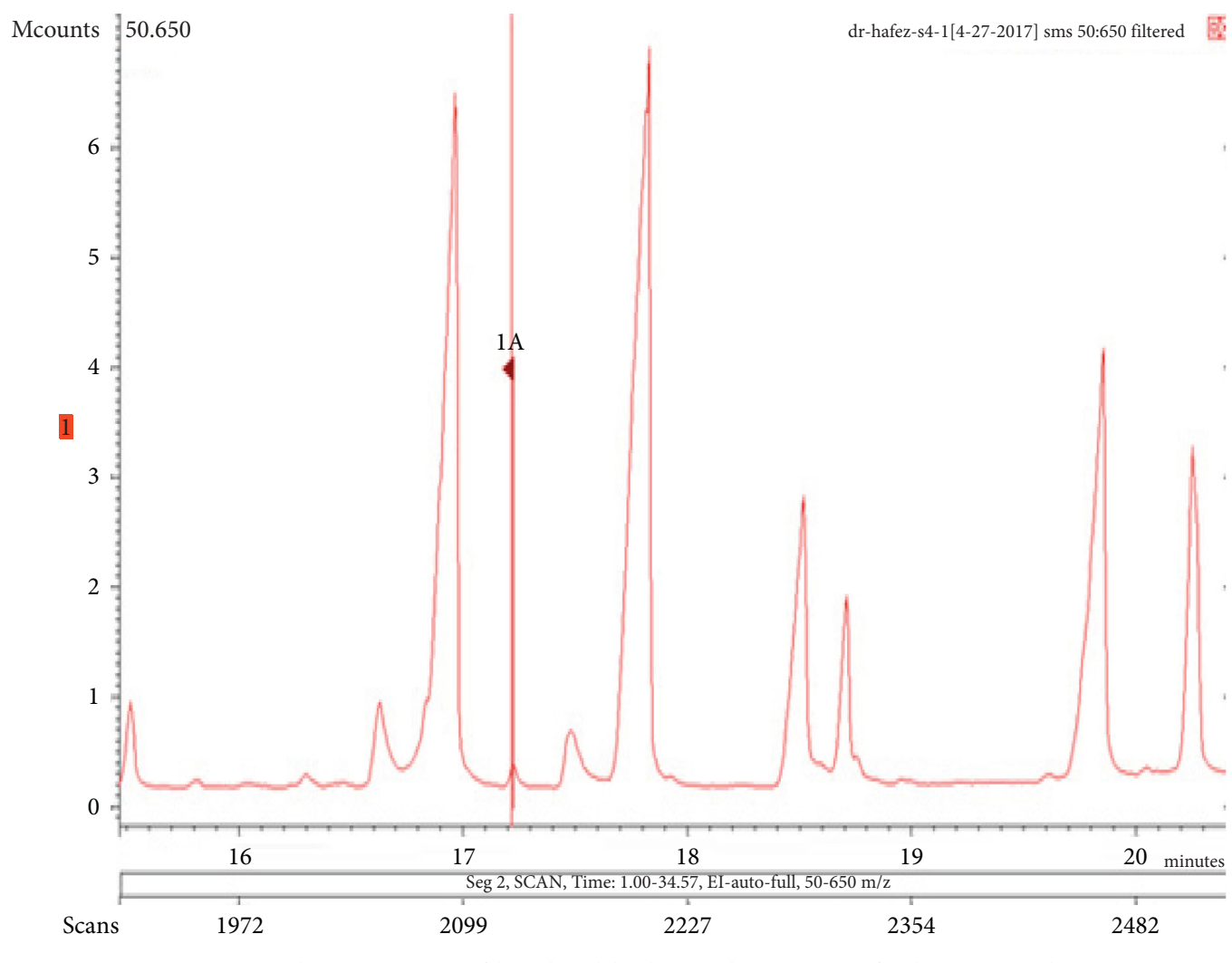

Figure 13: Chromatogram of butylated hydroxytoluene in air freshener sample 4.

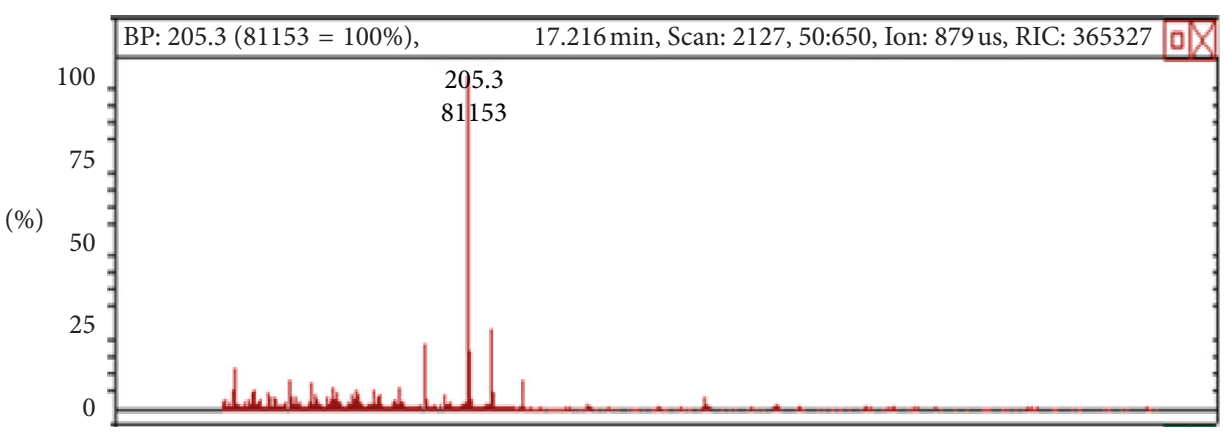

(a)

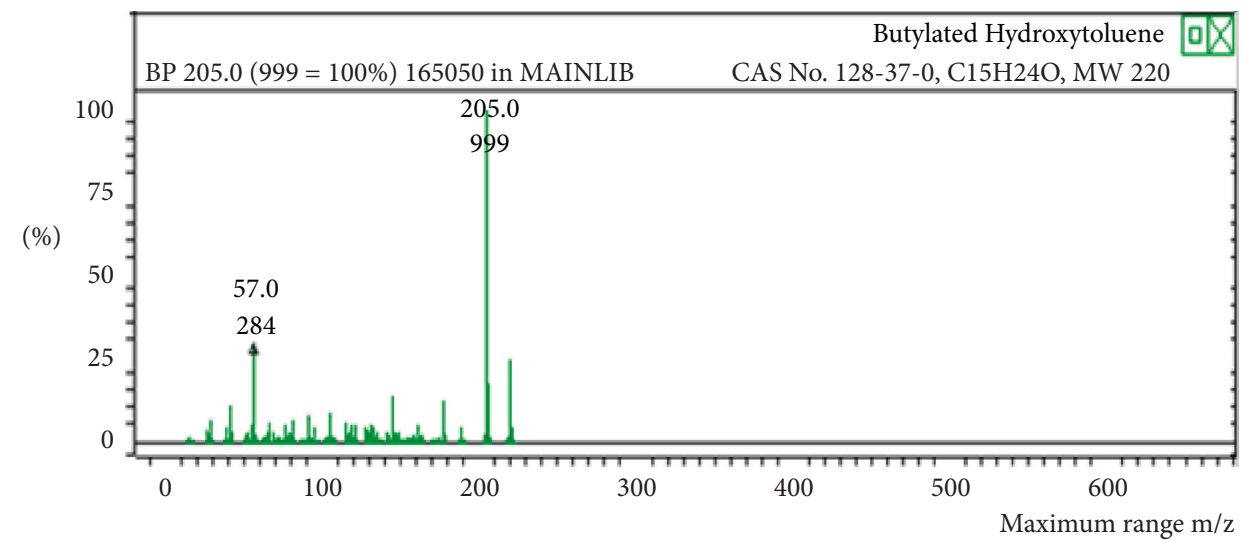

(b)

FIgURe 14: Mass spectrum of butylated hydroxytoluene in air freshener sample 4. (a) Air freshener analysis. (b) Main library of NIST11. 

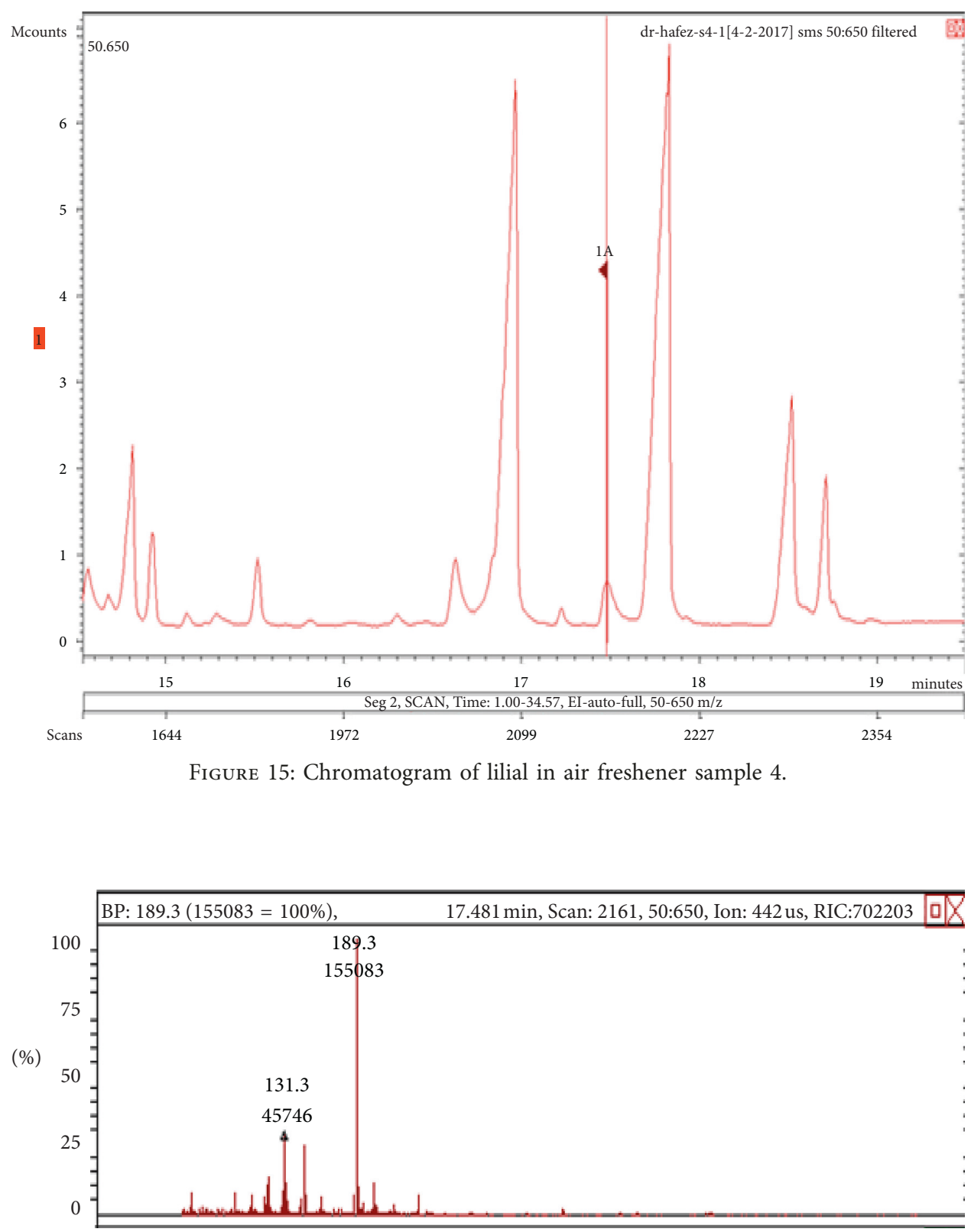

(a)

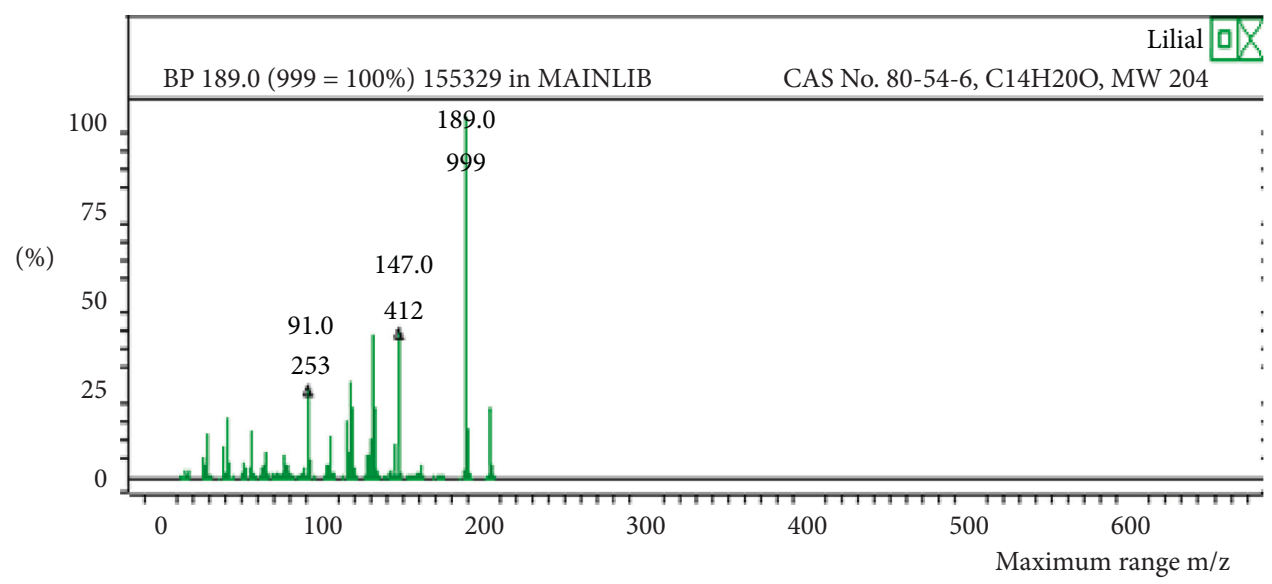

(b)

FIgURE 16: Mass spectrum of lilial in air freshener sample 4. (a) Air freshener analysis. (b) Main library of NIST11. 


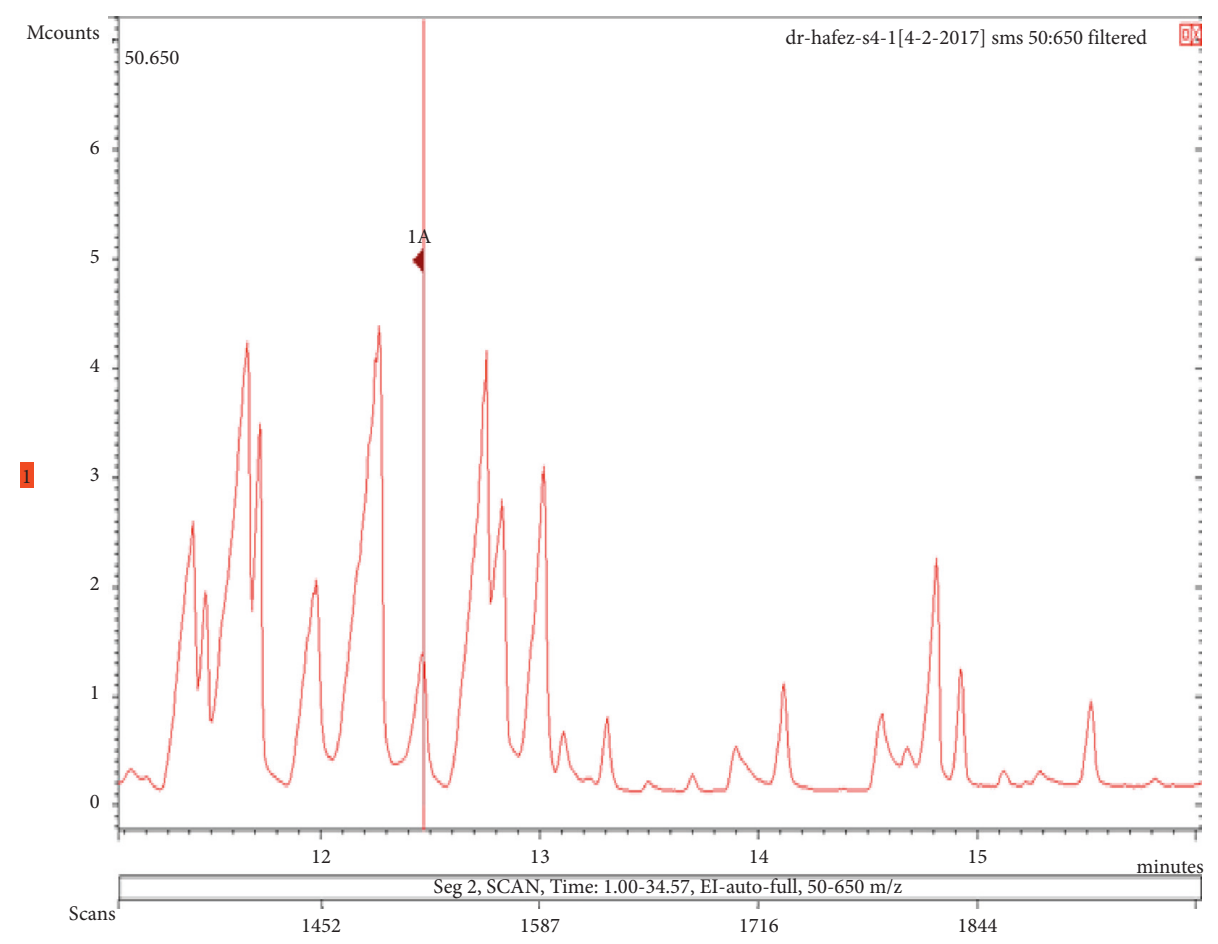

Figure 17: Chromatogram of linalool in air freshener sample 4.

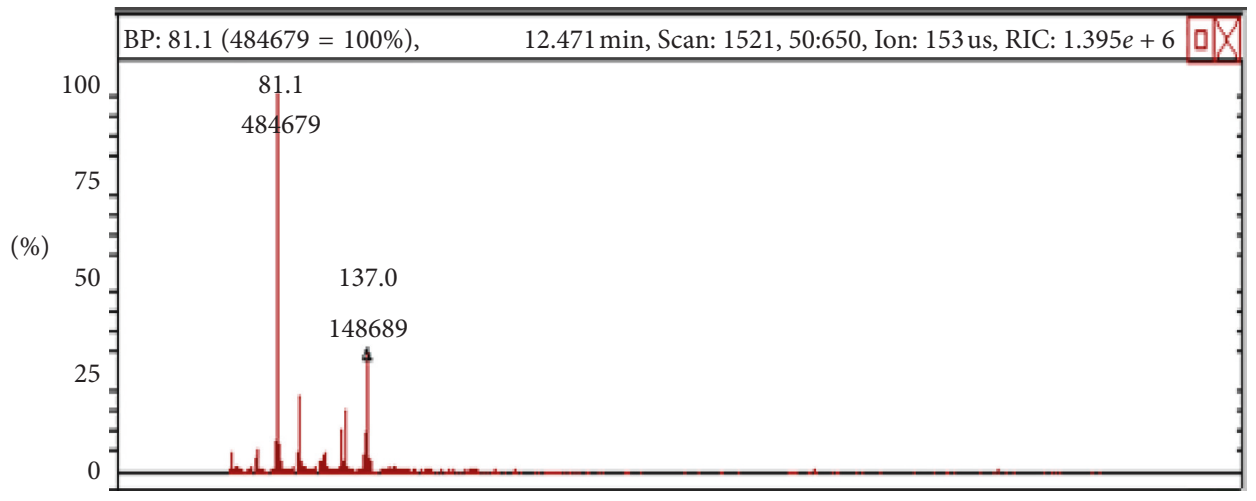

(a)

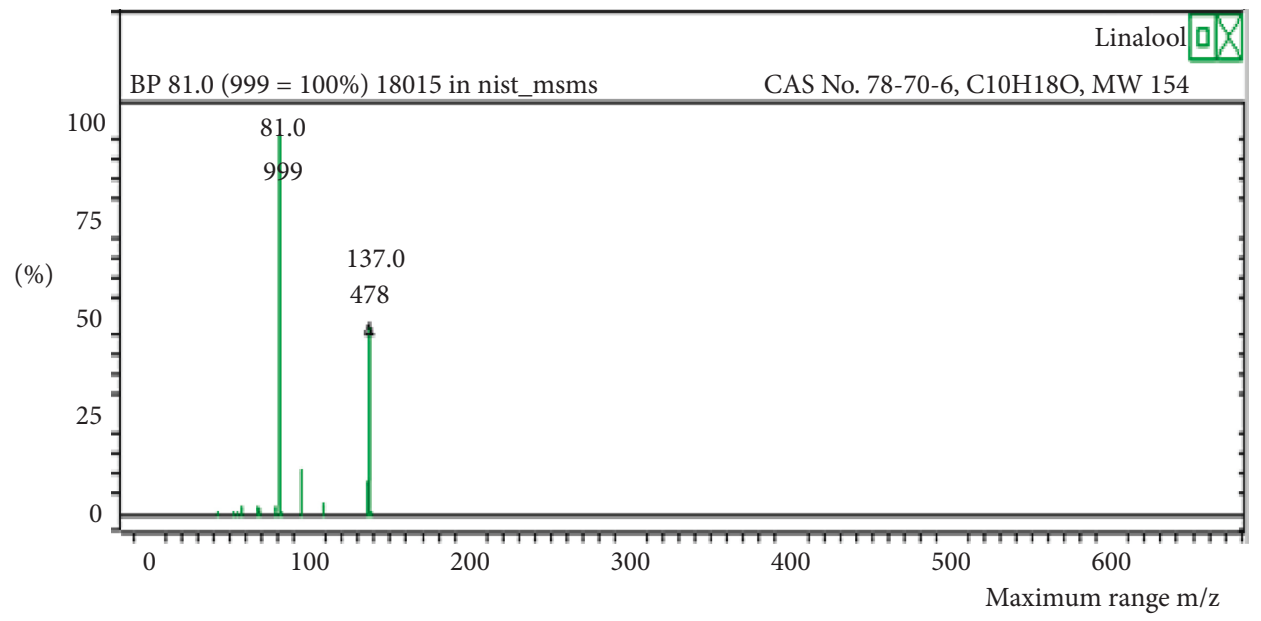

(b)

FIgURE 18: Mass spectrum of linalool in air freshener sample 4. (a) Air freshener analysis. (b) Main library of NIST11. 
(ii) Target 5000

(iii) Prescan ionization time $1500 \mu \mathrm{s}$

(iv) Scan time $0.66 \mathrm{~s}$

(v) Scan mode $(50-650 \mathrm{M} / \mathrm{z})$

(vi) Ion trap temperature was at $200^{\circ} \mathrm{C}$

(vii) Transfer line temperature $220^{\circ} \mathrm{C}$

(viii) Manifold temperature at $45^{\circ} \mathrm{C}$.

Finally, the National Institute of Standards and Technology 05 (NIST) mass spectral library was used for the identification of the obtained peaks. Table 1 shows brief description of each chemicals used in sample freshener.

\section{Results}

The chemicals found after the analysis of the four spray air fresheners include galaxolide, lilial, benzenemethanol, musk ketone, butylated hydroxytoluene (BHT), and linalool. The chromatograms with peaks representing each component found in the samples, along with their boiling points and molecular weights have been illustrated in Figures 1-18.

Table 2 presents the product labels that were labeled and not labeled on the air fresheners. Some chemicals after analysis turned out to be noted as skin allergens or irritants and even chemicals that may interfere with bodily functions. Some other chemicals found were safe to use in fragrance and household products and did not pose any health risk.

\section{Discussion}

The frequent use of air fresheners containing such synthetic chemicals may cause health effects on the long run; although exact concentrations of the chemicals present are not known. The present study has not included any laboratory tests or assessment regarding the potential health effects of air fresheners, as the main emphasis was on the identification of the chemical compounds found in the products. Lilial is found among two of the four samples analyzed that can sometimes act as an allergen and cause contact dermatitis in susceptible individuals [15]. The Campaign for Safe Cosmetics and The Environmental Working Group confirmed that Lilial is found in fragrance products, such as perfumes, colognes, and body sprays [16]. Galaxolide was found in two of the medium-to-high cost air fresheners. This chemical may interfere with hormones and other chemical signals in the body resulting in developmental, reproductive, metabolic, brain, and behavioural problems. Women's Voice for the Earth (WVE) revealed the presence of this chemical in cleaning products, including air fresheners [17].

Benzenemethanol, also known as benzyl alcohol, was found in both the low-cost and medium-to-high cost air fresheners. It is a known irritant when used in cosmetics and causes many problems and abnormalities. The Danish Environmental Protection Agency confirmed the presence of benzyl alcohol in specific fragrance ingredients used in air fresheners and other fragrance liberating products [18]. A previous study undertaken by The Campaign for Safe
TABLE 2: Labeling chemicals present in the four samples of air fresheners.

\begin{tabular}{lc}
\hline Air Freshener Sample 1 & \\
Aqua & Labeled \\
Isopropyl alcohol & Labeled \\
PEG 40 hydrogenated castor oil & Labeled \\
Parfum & Labeled \\
Lilial & Not labeled \\
Galaxolide & Not labeled \\
\hline Air Freshener Sample 2 & \\
Aqua & Labeled \\
Alcohol surfactant & Labeled \\
Fragrance & Labeled \\
Preservative & Labeled \\
Malodour counteracting (MOC) ingredient & Labeled \\
Antifoam & Labeled \\
Galaxolide & Not labeled \\
Benzenemethanol & Not labeled \\
\hline Air Freshener Sample 3 & \\
Butane & Labeled \\
SD alcohol 40-B & Labeled \\
Propane & Labeled \\
Fragrance & Labeled \\
Water & Labeled \\
Butylene glycol & Labeled \\
Camellia sinensis leaf extract & Labeled \\
Musk ketone & Not labeled \\
Benzenemethanol & Not labeled \\
\hline Air Freshener Sample 4 & Labeled \\
Butane & Labeled \\
Propane & Labeled \\
Isobutane & Not labeled \\
Alcohol & Labeled \\
Parfum & \\
Lilial & \\
Linalool & \\
Butylated hydroxytoluene (BHT) & \\
\hline &
\end{tabular}

Cosmetics along with The Environmental Working Group found that BHT and musk ketone were present in fragrance products $[19,20]$. Both of these chemicals are associated with estrogenic effects. BHT and musk ketone were found to be present only in the low-cost air fresheners. Finally, linalool is considered to be safe unless found in the oxidized form and causes skin reactions [20]. In the present study, this chemical was found in the low-cost air freshener only. A previous study by Steinemann [6] confirmed that linalool, a terpenoid, is emitted by air fresheners.

Previous studies have used other prevalent volatile organic compounds (VOC) such as acetaldehyde, ethanol, beta-myrcene, acetone, beta-pinene, limonene, and alphapinene in at least $40 \%$ of the products. Similarly, ethanol, acetaldehyde, alpha pinene, phenoxyethanol, limonene, and ethyl butyrate were the six most prevalent VOC's in building materials detected by GC/MS [21, 22]. These compounds, however, were not discussed and monitored in the present study. Furthermore, in air sampling, VOC's were not detected, which were obtained once daily from one site outside the hospital. Aromatic hydrocarbons such as ethylbenzene, toluene, and xylenes, esters (butyl acetate and ethyl acetate), and aliphatic hydrocarbons (n-hexane) 
were monitored and detected with TVOC concentrations surpassing the suggested maximum concentration ( $400 \mu \mathrm{g} / \mathrm{m} 3$ ) before occupying the building [23]. However, the study missed these chemicals or compounds to be monitored and detected, and thus failed to detect them in air fresheners sprays.

\section{Conclusion}

The present study has identified the presence of different compounds in spray air fresheners that were not disclosed on the product's label. The results depicted common compounds in both low- and high-cost air fresheners. Chemicals found in this study were not revealed on the product label as manufacturers are not required to list all ingredients. These chemicals usually tend to be listed on the product label as "parfum" or "fragrance". There should be a law that strictly indicates whether the products contain any synthetic chemicals for people to be aware of what they are exposed to, although, manufacturers are not required to reveal all hidden ingredients on the label as stated by the Consumer Product Safety Commission (CPSC). However, manufacturers should be encouraged to start producing air fresheners that are free from any synthetic and toxic chemicals, focusing on the use of natural ingredients instead. People must be aware that air fresheners come with unintended and perhaps invisible risks; therefore, the use of natural practices should be advocated to provide a pleasant ambience. A quantitative analysis of air fresheners is recommended as the present study has only focused on the qualitative analysis. Moreover, the enquiry included solely the emissions of primary VOC of each air freshener without the consideration of secondary pollutants. The limitations of this study were that the version of the GC/MS used was not able to detect highly volatile compounds, so different chemicals other than that detected could also be present in the four air fresheners. Furthermore, terpenes should be detected in future studies as they are found in high abundance. Further studies are needed to guarantee the safety of the product's content and whether present chemicals pose any health risk to humans and the environment.

\section{Data Availability}

The data (results of the measurements of toxic chemicals in the air fresheners) used to support the findings of this study are included within the article.

\section{Disclosure}

The ethical issues, including plagiarism, informed consent, misconduct, data fabrication and/or falsification, double publication and/or submission, and redundancy, have been completely observed by the authors.

\section{Conflicts of Interest}

The authors declare that there are no conflicts of interests regarding the publication of this manuscript.

\section{Acknowledgments}

The authors would like to express their gratitude to Mr. Muaath Khairi Mousa, the Laboratory officer at Research Institute of Science and Engineering (RISE) at the University of Sharjah, UAE, who provided expertise and help in the analysis of samples.

\section{References}

[1] M. Telpner, The Unfreshening Ingredients in Toxic Air Fresheners, 2016, https://www.meghantelpner.com/blog/ingredientsin-toxic-air-fresheners/.

[2] Y.-R. Jung, H.-H. Park, Y.-H. Oh et al., "Emission characteristics of volatile organic compounds from air fresher using small emission chamber," Journal of Korean Society of Environmental Engineers, vol. 33, no. 3, pp. 183-190, 2011.

[3] A. Cohen, S. Janssen, and G. Solomon, Clearing the Air: Hidden Hazards of Air Fresheners, 2007, https://www.nrdc. org/sites/default/files/airfresheners.pdf.

[4] NRDC, Clearing the Air: Hidden Hazards of Air Fresheners, National Resources Defense Council, New York, NY, USA, 2007, https://www.nrdc.org/sites/default/files/airfresheners.pdf.

[5] A. C. Steinemann, I. C. MacGregor, S. M. Gordon et al., "Fragranced consumer products: chemicals emitted, ingredients unlisted," Environmental Impact Assessment Review, vol. 31, no. 3, pp. 328-333, 2011.

[6] A. Steinemann, "Ten questions concerning air fresheners and indoor built environments," Building and Environment, vol. 111, pp. 279-284, 2017.

[7] A. Steinemann, "Fragranced consumer products: exposures and effects from emissions," Air Quality, Atmosphere \& Health, vol. 9, no. 8, pp. 861-866, 2016.

[8] S. M. Caress and A. C. Steinemann, "Prevalence of fragrance sensitivity in the American population," Journal of Environmental Health, vol. 71, no. 7, pp. 46-50, 2009.

[9] Yuningtyaswari and S. A. Dwi, "The effects of air freshener exposure at an early age on histological white rat (Rattus norvegicus) liver cells," in AIP Conference Proceedings, vol. 1744, no. 1, Article ID 020064, AIP Publishing, Yogyakarta, Indonesia, June 2016.

[10] United States Environmental Protection Agency (USEPA), Questions about Your Community: Indoor Air, USEPA, Washington, DC, USA, 2013.

[11] C. Solal, C. Rousselle, C. Mandin, J. Manel, and F. Maupetit, "VOCs and formaldehyde emissions from cleaning products and air fresheners," in Proceedings of the Indoor Air 2008, 11th International Conference on Indoor Air Quality and Climate, Copenhagen, Denmark, August 2008.

[12] W. H. Cheng, D. Y. Tsai, J. Y. Lu, and J. W. Lee, "Extracting emissions from air fresheners using solid phase microextraction devices," Aerosol and Air Quality Research, vol. 16, no. 10, pp. 2362-2367, 2016.

[13] N. A. Ashford and C. Miller, Chemical Exposures: Low Levels and High Stakes, Van Nostrand Reinhold, New York, NY, USA, 1998.

[14] L. A. Wallace, "Comparison of risks from outdoor and indoor exposure to toxic chemicals," Environmental Health Perspectives, vol. 95, pp. 7-13, 1991.

[15] A. Schnuch, W. Uter, J. Geier, H. Lessmann, and P. J. Frosch, "Sensitization to 26 fragrances to be labelled according to current European regulation," Contact Dermatitis, vol. 57, no. 1, pp. 1-10, 2007.

[16] H. Sarantis, O. V. Naidenko, and S. Gray, Not So Sexy: The Health Risks of Secret Chemicals in fragrance, Breast Cancer 
Fund CaEWG, Washington, DC, USA, 2010, http://www.ewg. org/sites/default/files/report/SafeCosmetics_FragranceRpt.pdf.

[17] Galaxolide: A Long-Lasting Fragrance Contaminating the Great Lakes, January 2019, http://www.womensvoices.org/fragranceingredients/galaxolide-a-long-lasting-fragrance-contaminatingthe-great-lakes/.

[18] J. Pors and R. Fuhlendorff, "Mapping of chemical substances in air fresheners and other fragrance liberating products. Survey on chemical substances in consumer products," Survey, vol. 30, 2003.

[19] J. L. Reiner, C. M. Wong, K. F. Arcaro, and K. Kannan, "Synthetic musk fragrances in human milk from the United States," Environmental Science \& Technology, vol. 41, no. 11, pp. 3815-3820, 2007.

[20] Linalool, 2016, http://www.tech-faq.com/linalool.html.

[21] H. Kataoka, Y. Ohashi, T. Mamiya et al., "Indoor air monitoring of volatile organic compounds and evaluation of their emission from various building materials and common products by gas chromatography-mass spectrometry," Advanced Gas Chromatography - Progress in Agricultural, Biomedical and Industrial Applications, InTechOpen, London, UK, 2012.

[22] N. Nematollahi, A. Doronila, P. J. Mornane, A. Duan, S. D. Kolev, and A. Steinemann, "Volatile chemical emissions from fragranced baby products," Air Quality, Atmosphere \& Health, vol. 11, no. 7, pp. 785-790, 2018.

[23] Y. Huang, S. S. H. Ho, K. F. Ho et al., "Characterization of biogenic volatile organic compounds (BVOCs) in cleaning reagents and air fresheners in Hong Kong," Atmospheric Environment, vol. 45, no. 34, pp. 6191-6196, 2011. 


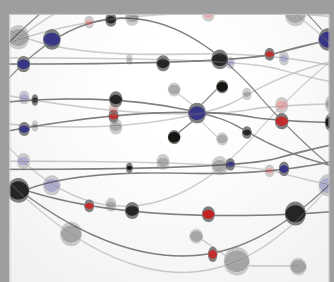

The Scientific World Journal
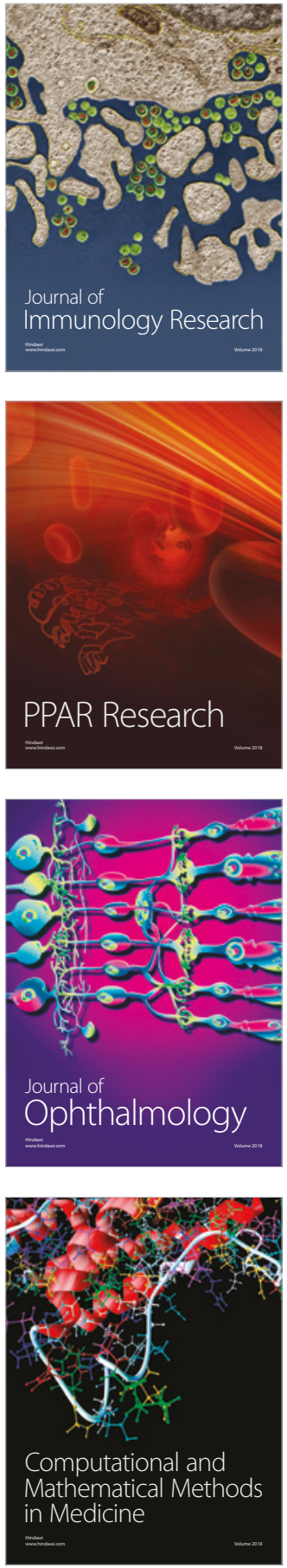

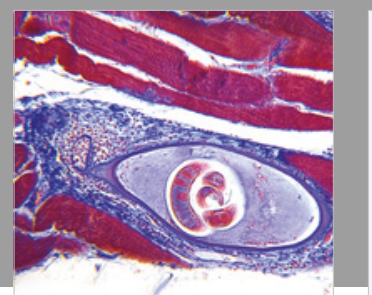

Gastroenterology Research and Practice

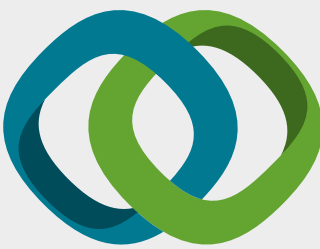

\section{Hindawi}

Submit your manuscripts at

www.hindawi.com
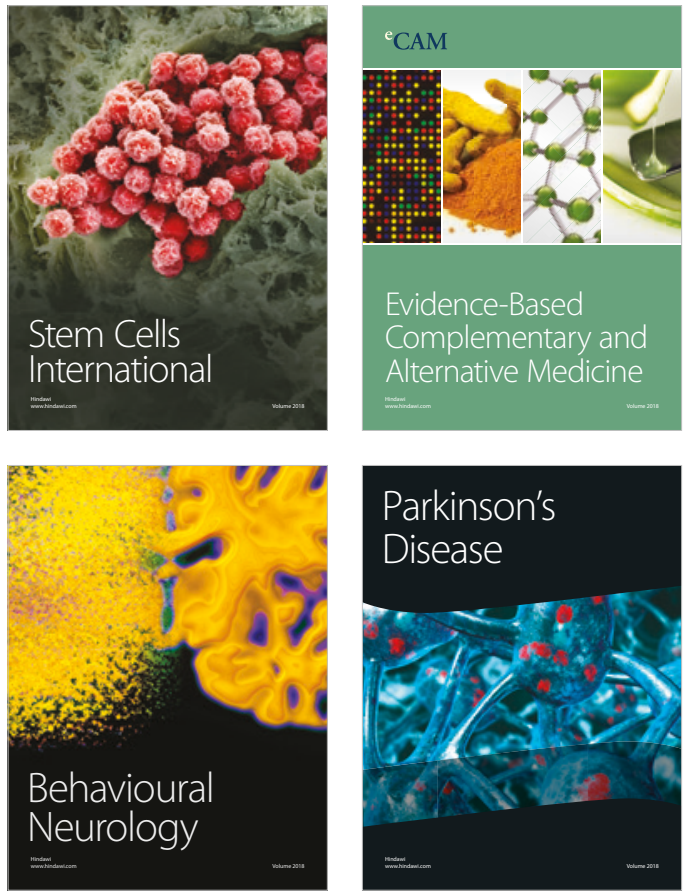

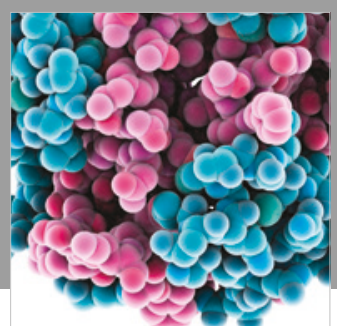

ournal of

Diabetes Research

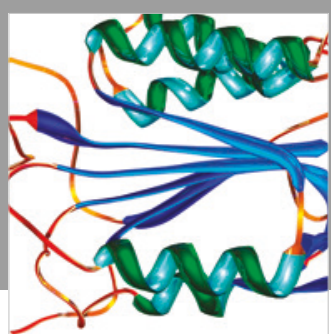

Disease Markers
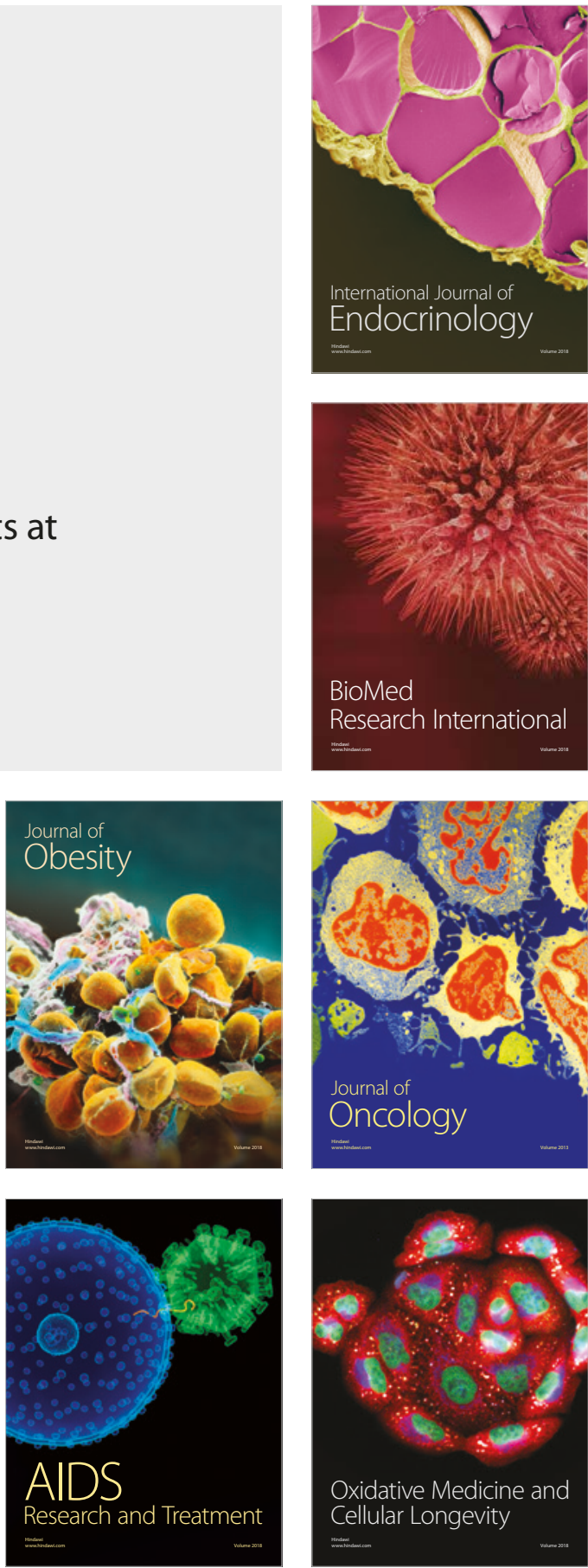